\title{
A MODEL FOR RESIDUAL STRESS EVOLUTION IN AIR-PLASMA-SPRAYED ZIRCONIA THERMAL BARRIER COATINGS*
}

\author{
B. G. Nair, J. P. Singh, and M. Grimsditch** \\ Energy Technology Division \\ **Materials Science Division \\ Argonne National Laboratory \\ Argonne, IL 60439
}

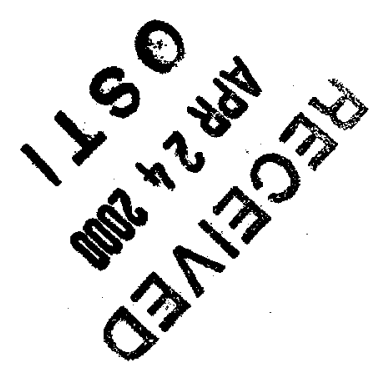

February 2000

\begin{abstract}
The submitted manuscript has been created by the University of Chicago as Operator of Argonne National Laboratory ("Argonne") under Contract No. W-31-109-ENG-38 with the U.S. Department of Energy. The U.S. Government retains for itself, and others acting on its behatt, a paid-up, nonexclusive. irrevocable wondwide license in said article to reproduce, prepare derivative works, distribute copies to the public, and perform publicly and display publicty, by or on behalf of the Government.
\end{abstract}

For publication in Proceedings of 24th Annual Cocoa Beach Conference on Engineering Ceramics and Structures, American Ceramic Society, Cocoa Beach. FL, Jan. 23-28, 2000.

*Work supported by the U.S. Department of Energy (DOE), Office of Industrial Technologies, under Contract W-31-109-Eng-38. 


\section{DISCLAIMER}

This report was prepared as an account of work sponsored by an agency of the United States Government. Neither the United States Government nor any agency thereof, nor any of their employees, make any warranty, express or implied, or assumes any legal liability or responsibility for the accuracy, completeness, or usefulness of any information, apparatus, product, or process disclosed, or represents that its use would not infringe privately owned rights. Reference herein to any specific commercial product, process, or service by trade name, trademark, manufacturer, or otherwise does not necessarily constitute or imply its endorsement, recommendation, or favoring by the United States Government or any agency thereof. The views and opinions of authors expressed herein do not necessarily state or reflect those of the United States Government or any agency thereof. 


\section{DISCLAIMER}

Portions of this document may be illegible in electronic image products. Images are produced from the best available original document. 
13. (i. Nair. J. P. Singh. and M. Grimsditch

Argomne National Laboratory

9700 South Cass Avenue

Argonne. IL 60439

\begin{abstract}
Ruby fluorescence spectroscopy indicates that residual stress in air-plasma-sprayed zirconia thermal barrier coatings is a function of the local interface geometry. The stress profile of a simulated rough interface characterized by "peaks" and "valleys" was modeled with a finiteelement approach that accounted for thermal mismatch, oxide scale growth, and top coat sintering. Dependence of the stress profile on interface geometry and microstructure was investigated. and the results were compared with measured stresses.
\end{abstract}

\title{
INTRODUCTION
}

Zirconia thermal barrier coatings (TBCs) are exciting prospective material systems for use in turbines and engines to increase their operating temperatures (by $100-200^{\circ} \mathrm{C}$ ) above those permitted by uncoated Ni-based superalloys. ${ }^{1}$ Reliable lifetime prediction models are essential for successful incorporation of TBCs in such high-temperature applications. Because failure of plasma-sprayed TBCs is generally due to damage initiated near the top coat/bond coat interface, ${ }^{2-}$ 4 measurement of residual stress near the interface is critical to understanding TBC failure. To this end. residual stress measurement in the oxide scale through ruby fluorescence spectroscopy is a powerful tool in analyzing local stress states. ${ }^{5-7}$ However, the utilization of these results for failure prediction requires numerical modeling of the state of stress at the top coat/bond coat interface.

Residual stresses developed in the oxide scale are the net result of a variety of factors such as thermal mismatch between constituents, oxide scale growth during processing and service, sintering of the top coat, plasticity and creep of the constituents (primarily the bond coat and substrate), and damage/microcracking in the top coat and oxide scale. Transient thermal stresses are superimposed onto these residual stresses during service. The resulting stresses lead to initiation and growth of localized damage (microcracking) at the top coat/bond coat interface. These stresses in the TBC are greatly influenced by interface geometry and microstructural features that result in stress concentrations at various locations. ${ }^{8}$ Thus, the key to understanding failure in plasma-sprayed coatings is in quantifying the effect of the wavy interface on local stress evolution in the top coat and scale. Analytical and numerical work has been performed on stress modeling in TBCs based on thermal mismatch considerations. ${ }^{9,10}$ In the present study, in addition to thermal stresses, oxide-growth-induced and top-coat-sintering-induced stresses are considered. In a recent study by Freborg et al, "I stresses due to oxide growth were evaluated by assigning an artificially high coefficient of thermal expansion (CTE) to the oxide scale and then simulating oxide volume expansion by imposing a small temperature change at steady state. While this approach is useful in estimating the stresses in the top coat and bond coat due to oxide growth. our model is directed at estimating stresses in the oxide scale itself in order to understand the results of stress/strain measurements in $\mathrm{Al}_{2} \mathrm{O}_{3}$ scale by ruby spectroscopy.

\section{NUMERICAL MODEL: MESH DESIGN AND MATERIALS PROPERTIES}

This numerical model evaluates stresses at a wavy interface (consisting of peaks and valleys) that simulates the interface geometry of plasma-sprayed coatings (Fig. 1). The TBC under consideration is divided into a number of unit cells, each of which is designed to include one-half of a peak and one-half of the adjacent valley, as shown in Fig. 1. Adjacent unit cells are mirror images of the unit cell under consideration. Stress states at symmetrical locations on either side 
of the mirror-planc are identical. A pair of adjacent unit cells (mirror images) constitutes a building block that is repeated throughout the entire coating. Therefore. information can be obtained about the entire coating through analysis of a single unit cell in our model. The physical dimensions of the peaks and valleys can be varied as desired. providing added flexibility to the model. () ther variables include processing temperature $\left(T_{p}\right) ;$ oxidation/service temperature $\left(T_{o, x}\right)$; volume shrinkage of the $\mathrm{ZrO}_{2}$ top coat; and thickness of the $\mathrm{ZrO}_{2}$, bond coat. and oxide scale.

Thermal strains for each element are input as $\alpha_{1}\left(T-T_{0}\right)$, where $\alpha_{1}$ is the CTE of the constituent materials (namely $\mathrm{ZrO}_{2}, \mathrm{Al}_{2} \mathrm{O}_{3}$, or the metallic bond coat) and $T$ is the temperature at which the stress is evaluated. $T_{0}$ is the equilibrium temperature for each constituent $\left(T_{o}=T_{p}\right.$ for the top coat and bond coat, and $T_{o}=T_{o x}$ for the oxide scale). The effect of the substrate is factored into the model by imposing the constraint that, at any temperature, the length of the unit cell edge in contact with the substrate is determined by the linear expansion/contraction of the substrate. It is assumed that the thickness of the substrate is substantially greater than the thickness of the top coat and bond coat layers. For $T$ equal to room temperature, the stresses computed by the model are directly comparable to the stresses measured by ruby fluorescence spectroscopy. Compatibility requirements provide the boundary condition that the vertical unit cell edges remain straight at all temperatures. For these calculutions, the top coat and bond coat were assumed to be free of thermal strain at the processing temperature (assumed to be $700^{\circ} \mathrm{C}$ ) of the TBC and the oxide scale was assumed to be thermal strain-free at the oxidation temperature (assumed to be $1150^{\circ} \mathrm{C}$ ).

Oxidation of $\mathrm{Al}$ from the bond coat to form $\mathrm{Al}_{2} \mathrm{O}_{3}$ is accompanied by a volume change. Due to the geometry of the rough interface, strain due to volume change cannot be relieved by simple translation of the top coat, as would be the case for a flat interface. Therefore, an initial volume strain $\left(\varepsilon_{0, o x}\right)$ was assigned for each element in the thermally grown oxide scale. The unit cell was allowed to deform elastically to relieve these initial strains, and the resulting stresses and strains in the TBC system were evaluated. An oxide growth factor $\left(G_{o x}\right)$ was introduced to account for the directionality of oxide growth defined as $G_{o x}=\varepsilon_{0, N}\left(\varepsilon_{o, N}+\varepsilon_{0, T}\right)$, where $\varepsilon_{0, V}$ is the initial normal (radial) strain imposed on the oxide scale and $\varepsilon_{0, T}$ is the initial tangential strain $\left(\varepsilon_{0 . Y}+\varepsilon_{0 . T}=\varepsilon_{0, o x}\right)$. It is expected that most of the growth occurs in the direction of least resistance (i.e.. the normal direction). and therefore $G_{o x}$ was taken as 0.95 for this set of calculations.

Stresses due to sintering of the top coat are modeled in a similar manner by imposing an initial volume strain on the top coat elements corresponding to the volume shrinkage of the top coat due to sintering. The initial strains due to sintering are compressive, whereas the initial strains due to oxide growth are tensile.

The model is designed to be executed with Mathematica 4.0 software. Quadrilateral isoparametric elements with a variable number of nodes (4-8) are used to form the finite-element mesh. Eightnode elements are used for the oxide scale for increased accuracy of stress computation at the interface. as shown in Fig. 1. The program is designed to generate finer elements at locations closer to the thermally grown oxide and the top coat/bond coat interface. Based on the abovediscussed numerical model, normal and shear stresses for each element were calculated. Subsequently, these stresses were used to estimate hydrostatic stresses in the TBC sy stem. The elastic constants (elastic modulus, $E=200$, Poisson's ratio, $v=0.3$ ) and $C T E, \alpha=8 \times 10^{-6} / \mathrm{K}$ for zirconia used in this calculation are typical values expected for a top coat with accumulated damage. The bond coat is assumed to have the following properties: $E=200 \mathrm{GPa}, v=0.3$ and $\alpha=17 \times 10^{-6} / \mathrm{K}$. Based on preliminary observations of significant porosity in the thermally grown $\mathrm{Al}_{2} \mathrm{O}_{3}$ scale, its property values were taken to be: $\mathrm{E}=200 \mathrm{GPa}, v=0.3$ and $\alpha=8 \times$ $10^{\circ} / \mathrm{K}$. Many of the property values used in these preliminary calculations are approximate numbers and were used to provide general trends in the stress variation with microstructure of TBCs and their subsequent comparison with measured trends. Accuracy of the stress values will depend on the accuracy of the property values used. 
RESUI,TS $\triangle$ NI) DISCUSSION

The oxide scale represented by the strip A-B-C-D in Fig. 1 is divided into 16 elements numbered I through $16(A$ being 1 and $D$ being 16). Figure 2 shows the deformed unit cell resulting from thermal mismatch alone and stress contours in the top coat. bond coat, and oxide scale. The stresses in the $x$ - and $y$-directions $\left(\sigma_{x x}\right.$ and $\sigma_{y y}$ ) and the hydrostatic stress $\left(\sigma_{m y t}\right)$ in each element are functions of $x$ and $y$ coordinates: stresses shown in Fig. 2 are the values calculated at the centroid of each element. Stresses in the figure can be estimated by using the gray scale indicated. For the sake of clarity, the displacements shown in the figure have been multiplied by a factor of 10. Figure 3 shows the variation of normal, tangential, and hydrostatic stresses in the oxide scale stress as a function of spatial location (element numbers). The comprc.....: hydrostatic stresses due to thermal mismatch seem to be maximized in element 9 (point $C$ in Fig. 1) due to the high tangential stresses resulting from thermal mismatch between the bond coat and scale. The stress trends, in general. seem to be in agreement with expected stress distributions from thermal mismatch considerations at wavy interfaces. 8,9

The effect of top-coat sintering ( 3 vol.\% shrinkage) at operating temperature on residual stresses in the oxide scale is shown in Fig. 4. Interestingly, the stress distribution generated is characterized by nearly equal and opposite normal and tangential stresses across the length of the oxide scale. Therefore, the hydrostatic stresses are relatively low compared to the magnitudes of the normal and tangential stresses. Because the ruby fluorescence technique measures hydrostatic stresses, this result suggests that the stress distribution due to sintering cannot be measured easily by this technique. However, because sintering results in locally high tensile stresses (e.g., 1.3 GPa in element 8), it is possible that sintering may play an important role in damage initiation in the oxide scale.

Figure 5 shows the variation in hydrostatic stress with spatial location in the oxide scale as a result of oxide growth alone. Initial strain $\varepsilon_{0,0 x}$ is taken as 0.2 for this calculation. The model predicts maximum compressive hydrostatic stress at the peaks (element 16) and minimum compressive stress at the valleys (element 1) of the rough interface. This predicted trend is in excellent agreement with the measured stress distribution by fluorescence spectroscopy. ${ }^{7}$ However. the magnitude of measured compressive stresses are lower than that predicted by the model. This difference may be due to (a) an overestimation during modeling of initial strains in the oxide scale, (b) stress relaxation due to bond coat plasticity at high temperature not accounted for in the model and (c) expected edge effects in the specimen resulting in a tensile stress perpendicular to the $x-y$ plane and therefore a lowering in the measured compressive hydrostatic stress.

\section{SUMMARY AND CONCLUSIONS}

Accurate interpretation of measured stress distributions in the thermally grown oxide scale by fluorescence spectroscopy can allow real-time damage monitoring in TBC systems. A finiteelement model was developed to estimate the stresses generated in the oxide scale of a thermal barrier coating (TBC) system considering thermal mismatch, oxide growth. and top coat sintering effects. The stresses due to thermal mismatch calculated by our model agree well with previous modeling work in TBC systems. Top coat sintering was shown to have only a mild effect on measured hydrostatic stresses by spectroscopy, but could have a signiticant role in danage initiation due to localized tensile stresses induced in the top coat and scale. Oxide growth (i.e.. radial or tangential) has a strong effect on overall stress distribution. The overall stress distribution is the resultant of stresses due to all three mechanisms (i.e., thermal mismatch. oxide growth. and top coat sintering).

ACKNOWLEDGMENT

Work was supported by the U.S. Department of Energy (DOE). Office of Industrial rechmologics. under Contract W-31-109-Eng-38. 


\section{REFERENCES}

'S. M. Gupta and D. K. Gupta, "The evolution of thermal barrier coatings in gas turbine applications," J. Engr. Gus Turb. Power, 111,301-5 (1989).

'D. Zhu and R. A. Miller, "Investigation of thermal high cycle and low cycle fatigue mechanisms of thick thermal barrier coatings," Mat. Sci. Engr. A, A245, 212-23 (1998).

3J. T. DeMasi-Marcin, K. D. Sheffler and S. Bose, "Mechanisms of degradation and failure in a plasma-deposited thermal barrier coating," J. Engr. Gas Turb. Power, 112, $521-26$ (1990).

${ }^{+}$J. P. Singh, M. Sutaria and A. Chopra, "Thermomechanical behavior of plasma-sprayed zirconia thermal barrier coatings," Ceram. Engr. Sci. Proc., 19 (4), 313-322 (1998).

${ }^{5}$ R. J. Christensen, D. M. Lipkin and D. R. Clarke, "Nondestructive evaluation of the oxidation stresses through thermal barrier coatings using $\mathrm{Cr}^{3+}$ piezospectroscopy," J. Appl. Phys. Lett., 69 (24), 3754-56 (1996).

${ }^{6}$ M. J. Lance, J. A. Haynes, W. R. Cannon and M. K. Ferber, "Piezospectroscopic characterization of thermal barrier coatings," Ceram. Trans. Nondestructive Evaluation of Ceramics, edited by C. H. Schilling and J. N. Gray, Am. Ceram. Soc. Inc., Westerville, OH, 89, 229-237 (1998).

'J.P. Singh, B.G. Nair, M. Sutaria, D. Renusch and M. Grimsditch, "Damage Evolution and Residual Stresses in Plasma-Sprayed Zirconia Thermal Barrier Coatings," Ceram. Sci and Engr. Proc., 20(3), 487-492 (1999).

${ }^{8}$ A. G. Evans, G. B. Crumley and R. E. Demaray, "On the mechanical behavior of brittle coatings and layers," Oxidation Met., 20 (5/6), 193-216 (1983).

${ }^{9}$ C-H. Hsueh, J. A. Haynes, M. J. Lance, P. F. Becher, M. K. Ferber, E. R. Fuller, Jr., S. A. Langer, W. C. Carter and W. R. Cannon, "Effects of Interface Roughness on Residual Stresses in Thermal Barrier Coatings," J. Amer. Ceram. Soc., 82 (4) 1073-75 (1999).

${ }^{10} \mathrm{G}$. J. Petrus and B. L. Ferguson, "A software tool to design thermal barrier coatings: A techniçal note," J. Plasma Spray Tech., 6 (1), 29-34 (1997).

A. M. Freborg, B. L. Ferguson, W. J. Brindley and G. J. Petrus, "Modeling oxidation-induced stresses in thermal barrier coatings," Mater. Sci. Engr. A, A245, 182-190 (1998). 


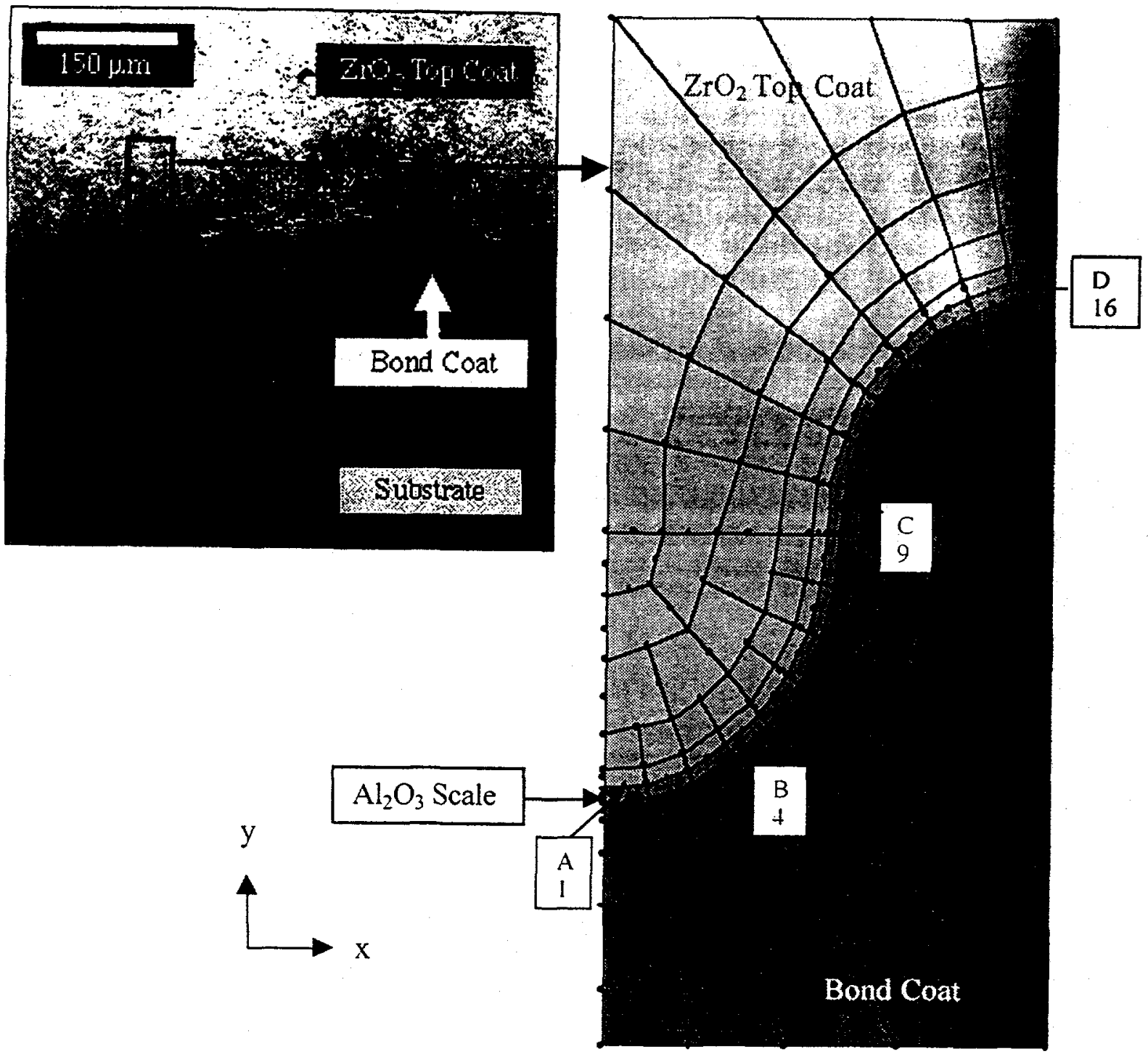

Fig. 1. Unit cell configuration (right) showing quadrilateral clements and its location with respect to a real top-coat/bond-coat interface (lefi) characterised hy peiks and valleys in a $\mathrm{ZrO}_{2}$ TBC system. The top coat, bond coat and wide sulk in the unit well are identified with different gray levels for clarity. Oxide scak is indicilcd he cur:- $1-13-C-D$. and elements are sequenced by numbers 1 through 16 incm. 111 ) 


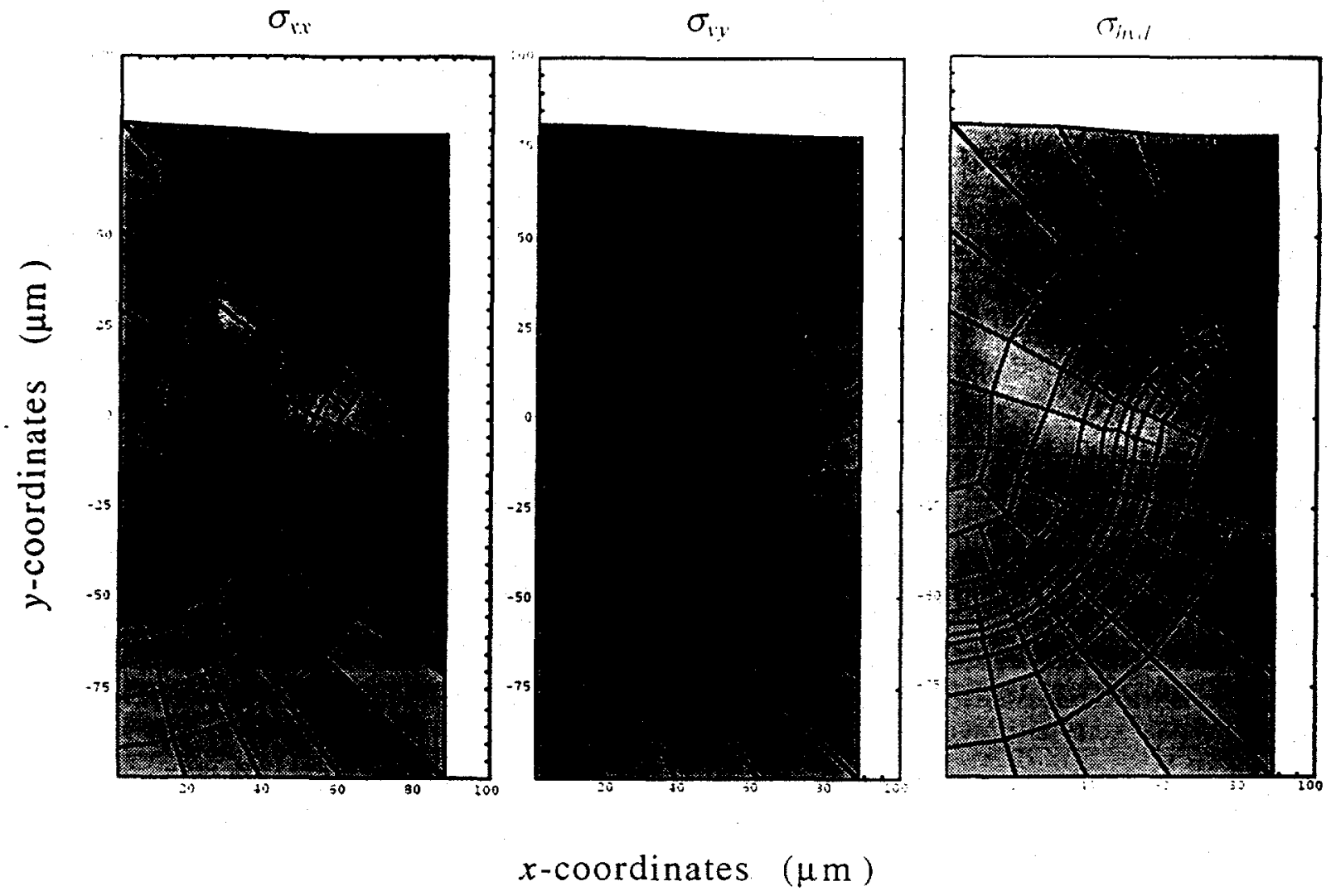

Stress Scale $(\mathrm{GPa})$
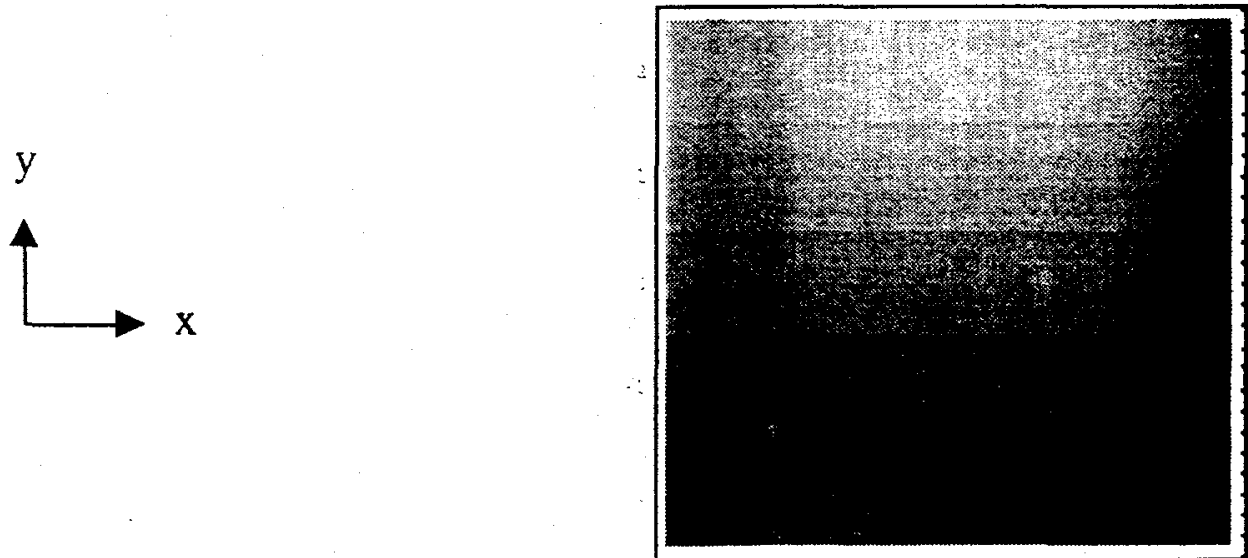

Fig. 2. Stress distribution generated at wavy top coat/bond incelice duc to thermal mismatch between constituents. Stresses can be estimated by comparison with grat levels indicated in stress scale. Nodal displacements are multiplied hy 10 (1) ckarly illustrate shape of deformed unit cell. Outer grid shows original dimensions af unil cell: 


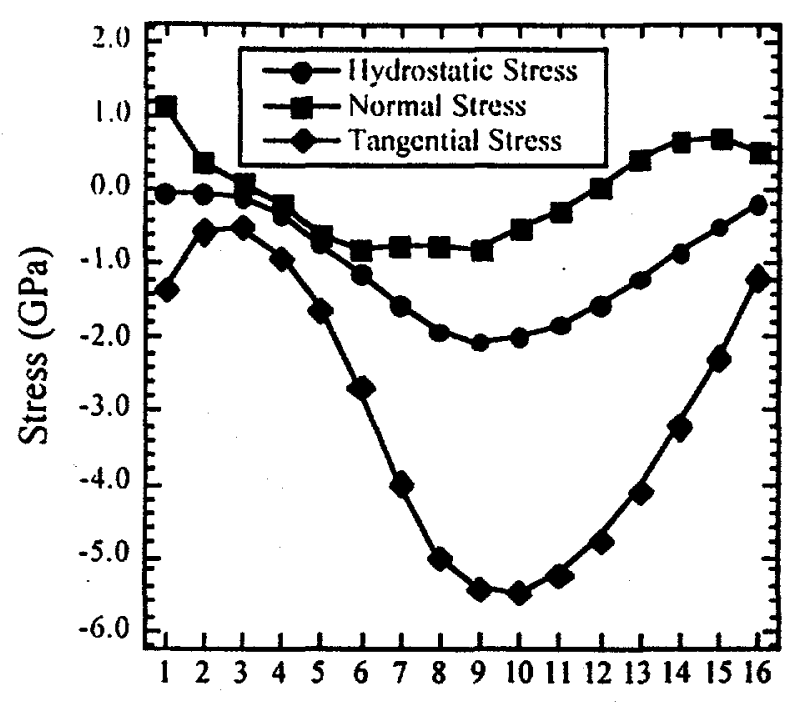

Spatial Location (Element Numbers)

Fig. 3. Variation of thermal-mismatch-induced normal, tangential, and hydrostatic stresses in oxide scale as a function of spatial location (element numbers).

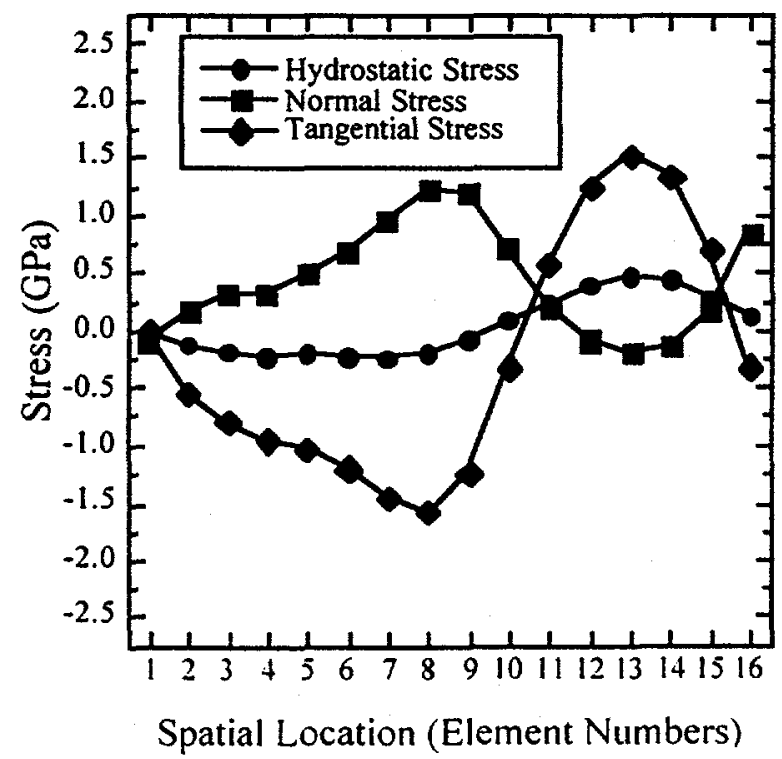

Fig. 4. Variation of sintering-induced normal, tangential, and hydrostatic stresses in oxide scale as a function of spatial location. 


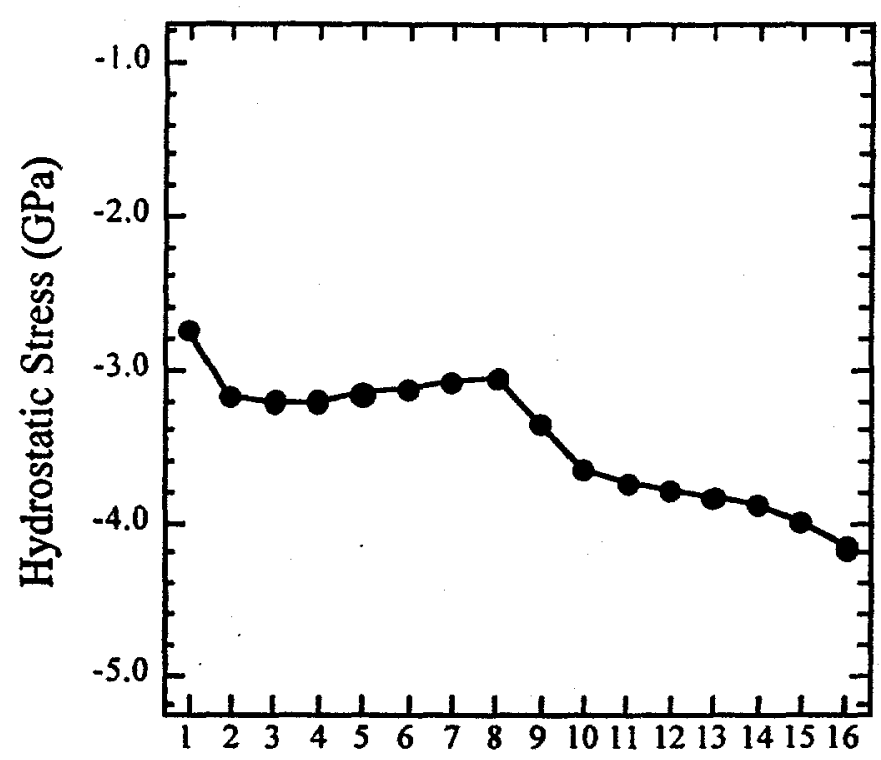

Spatial Location (Element Numbers)

Fig. 5. Variation of oxide-growth-induced hydrostatic stress in oxide scale as a function of spatial location. 